\title{
Functional outcome of surgical management in cases of fracture patella in a tertiary care hospital in Salem
}

\author{
Nikhilesh P. S. ${ }^{1}$, Hari Sivanandan ${ }^{2 *}$, Anandanarayan M. ${ }^{2}$, A. E. Manoharan ${ }^{3}$
}

\begin{abstract}
${ }^{1}$ A. C. S. R Government Medical College and Hospital, Nellore, Andhra Pradesh, India
${ }^{2}$ Vinayaka Mmission's Kirupananda Variyar medical college and research institute, Salem, Tamil Nadu, India

${ }^{3}$ Department of Orthopedics, Vinayaka Mission's Kirupananda Variyar medical college and hospital, Salem, Tamil Nadu, India
\end{abstract}

Received: 29 March 2021

Revised: 19 April 2021

Accepted: 23 April 2021

\section{*Correspondence:}

Dr. Hari Sivanandan,

E-mail: Arvidr84@gmail.com

Copyright: (C) the author(s), publisher and licensee Medip Academy. This is an open-access article distributed under the terms of the Creative Commons Attribution Non-Commercial License, which permits unrestricted non-commercial use, distribution, and reproduction in any medium, provided the original work is properly cited.

\section{ABSTRACT}

Background: Fractures of the patella are serious injuries with a broad range of subtypes. These injuries account for about $1 \%$ of all skeletal injuries and are most prevalent within the age group of 20-50 years. The underlying mechanisms of open fractures are mostly high-velocity accidents. To assess the functional outcome of various surgical procedures done for fracture patella.

Methods: A longitudinal study was conducted from the department of orthopedics, Vinayaka missions Kirupananda Variyar medical college and hospital, Salem for one year in August 2019 and July 2020. All the adult patients admitted with the diagnosis of patellar fracture were included in the study. A complete local examination was conducted and an X-ray of AP and the lateral view was taken for all the patients.

Results: Transverse patella fracture is being the most common fracture and for that modified tension band wiring (TBW) was the most common procedure performed and for comminuted fracture partial patellectomy was the most common procedure and for 1 patient total patellectomy was performed.

Conclusions: The study shows that the treatment of patella fractures with modified tension band wiring is a definitive treatment with minimal complications and excellent functional outcomes.

Keywords: Patella fracture, Tension band wiring, West criteria, Functional outcome

\section{INTRODUCTION}

Epidemiologic studies demonstrated that the incidence in men is twice as high as in women. Because of the subcutaneous anterior location, the biomechanical function, and the high level of force transmission during extension and flexion, stable reconstruction of patellar fractures continues to represent a major surgical challenge. ${ }^{1,2}$ The majority of cases are caused by a direct injury mechanism. The resulting fracture type depends on the trauma mechanism (i.e., direct or indirect), the energy transmitted to the bone, and the bone quality. ${ }^{3}$ The most common fracture pattern is a simple 2-part diversion caused by a direct blow (i.e., dashboard injury). As a result of the bony lesion, the extensor mechanism of the knee joint can become insufficient. ${ }^{4}$ The degree of the insufficiency depends among other factors on accompanying damage to the reserve extensor mechanisms. Additional injuries to the adjacent bones are rare but can affect the articular surface of the distal femur. ${ }^{5}$ The most frequent indirect mechanism is a fall on the feet with eccentrical contraction of the quadriceps muscle. Depending on the velocity of the fall and the resistance of the extensor mechanism, either the patella or the adjacent tendons fail. ${ }^{6}$ Closed fractures of the patella represent the vast majority of this injury. However, up to $7 \%$ of the cases 
result in open fractures. The underlying mechanisms of open fractures are mostly high-velocity accidents. ${ }^{7}$ These can result in devastating soft tissue conditions with comminuted fractures as well as additional ruptures of the reserve extensor mechanism. ${ }^{8}$ Of note, approximately $80 \%$ of open patellar fractures are associated with multiple accompanying injuries, namely fractures of the femur or acetabulum, traumatic dislocation of the hip joint, or disruption of knee ligaments. ${ }^{9}$ The most frequent causes are traffic accidents in $78.3 \%$, followed by work-related accidents in $13.7 \%$ and domestic accidents in $11.4 \%$. Sports-related fractures of the patella are relatively seldom. ${ }^{10}$

\section{METHODS}

A longitudinal study was conducted from the department of orthopedics, Vinayaka Missions Kirupananda Variyar medical college and hospital, Salem for one year in August 2019 and July 2020. All the adult patients admitted with the diagnosis of patellar fracture were included in the study. A total of 30 patients were included in the study. History is related to socio-demography, nature of trauma, whether due to direct or indirect violence was noted. The inquiry was made to note pain, swelling, its rate of increase, and if the patient was able to bear weight on the affected limb and was able to do active movements of the affected joint. A complete local examination was conducted and an X-ray of AP and the lateral view was taken for all the patients. Following operative procedures were performed based on their fracture pattern, the activity of the patient, and the functional expectations. All the patients after discharge were followed up regularly on $2^{\text {nd }}$ week, $6^{\text {th }}$ week, $3^{\text {rd }}$ month, and $6^{\text {th }}$ month postoperatively. The functional outcome was assessed using the West criteria grading system as excellent, good, or poor.

\section{Inclusion criteria}

All the adult patients admitted with the diagnosis of patella fracture were included in the study. All transverse fracture patella can be treated with either cerclage wiring, tension band wiring, or modified tension band wiring. All comminuted fracture patella can be treated with either cerclage wiring, modified tension band wiring, partial patellectomy, or total patellectomy. The polar fractured patella can be treated either with $\mathrm{K}$ wire fixation and tension band wiring or partial patellectomy.

\section{Exclusion criteria}

Compound fracture patella. Fracture patella associated with femoral condylar fracture. Fracture patella is associated with intra-articular and tibial plateau fractures were excluded from the study.

\section{Study procedure}

The study was started after getting clearance from the institutional ethical committee. Informed consent was obtained from all the patients involved in the study. Sociodemographic profile related to name, age sex, occupation, address, family history, and history was obtained from the patients. History related to the nature of trauma, whether due to direct or indirect violence was noted. Whether trauma due to road traffic accidents, assault, fall in the same plane, or fall from a height were specifically asked. An enquiry was made to note pain, swelling its rate of increase, and if the patient was able to bear weight on the affected limb and was able to do active movements of the affected joint.

\section{Local examination}

Inspection: Size, shape, and extent of the swelling, condition of the skin over the swelling, and presence of any contusion, abrasion, or laceration. Whether any sulcus present in the middle of the swelling.

Palpation: the local rise of temperature, tenderness over the bone, a palpable transverse sulcus, crepitus, fluctuation, and broadening of the patella. Active extension movements of the affected knee were noted compared with the normal side. It was also noted whether the patient was able to stand on his injured limb. The circumference of both the thighs was measured to note any reduction in the bulk of the quadriceps. The other knee joint was examined for comparison and to note any anatomical variation.

\section{Investigations}

Routine examination of blood and urine were done for hemoglobin percentage, total and differential WBC count, bleeding and clotting time, and presence of albumin and sugar in urine and $\mathrm{HbsAg}$, HIV tests.

\section{$X$-ray examination}

$\mathrm{X}$-rays in lateral and anteroposterior views were taken for confirmation of diagnosis. X-rays in skyline views were taken in cases suspected to have longitudinal and marginal fractures. After a proper anesthetic workup, the patients were taken up for surgery. The following were the procedures performed based on their fracture pattern, the activity of the patient, and the functional expectations. 1) $\mathrm{K}$-wire fixation and tension band wiring. 2) Lag screw fixation and tension band wiring. 3) Transverse lag screw with cerclage wiring. 4) Partial patellectomy. 5) Total patellectomy. Immediate post-op period complications were noted and addressed as per the requirements of the patients. All the patients after discharge were followed up regularly on $2^{\text {nd }}$ week, $6^{\text {th }}$ week, $3^{\text {rd }}$ month, and $6^{\text {th }}$-month postoperatively. The functional outcome was assessed using West's criteria which is graded.

\section{Statistical analysis}

All the data were entered and analyzed using SPSS version 22. Mean and standard deviation was derived for all the parametric variables and the percentage was derived for 
frequency variables. Chi-square test and Man-Whitney U test are the non-parametric tests used for deriving the statistical inference.

\section{RESULTS}

Table 1 shows the age-wise distribution of the study subjects. It is seen from the table that the majority of the study subjects were in the age group between 40 and 50 years with a mean age of 44.1 years. gender-wise distribution of the study subjects. It is seen from the table majority of the patients were males with a male:female ratio of $1.7: 1$.

Table 1: Age wise distribution of the study subjects.

\begin{tabular}{|lll|}
\hline Age group (year) & Frequency & Percentage (\%) \\
\hline $\mathbf{2 0 - 3 0}$ & 4 & 13.3 \\
\hline $\mathbf{3 1 - 4 0}$ & 6 & 20 \\
\hline $\mathbf{4 1 - 5 0}$ & 10 & 33.3 \\
\hline $\mathbf{5 1 - 6 0}$ & 8 & 26.6 \\
\hline$>$ 60 & 2 & 6.6 \\
\hline Total & 30 & 100 \\
\hline
\end{tabular}

Table 2: Distribution of the study subjects based on the side of the knee involvement.

\begin{tabular}{|lll|}
\hline Side of knee & Frequency & Percentage $(\%)$ \\
\hline Right knee & 18 & 60 \\
\hline Left knee & 12 & 40 \\
\hline Total & 30 & 100 \\
\hline
\end{tabular}

Table 2 shows the side of the knee involvement among the study subjects. It is seen from the table that right knee involvement was more common than the left knee.

Table 3: Distribution of the study subjects based on the nature of trauma.

\begin{tabular}{|lll|}
\hline Nature of trauma & Frequency & Percentage (\%) \\
\hline Direct impact & 20 & 66.6 \\
\hline Indirect impact & 10 & 33.3 \\
\hline Total & 30 & 100 \\
\hline
\end{tabular}

Table 3 shows the distribution of the study subjects based on the nature of trauma. It is depicted from the table that direct impact was a more common mode of trauma than indirect impact.

Table 4: Distribution of the study subjects based on the type of accident.

\begin{tabular}{|lll|}
\hline $\begin{array}{l}\text { Type of accident } \\
\text { Road traffic }\end{array}$ & Frequency & Percentage (\%) \\
accident & 16 & 53.3 \\
\hline $\begin{array}{l}\text { Fall in the same } \\
\text { plane }\end{array}$ & 8 & 26.6 \\
\hline Assault & 6 & 20 \\
\hline Total & 30 & 100 \\
\hline
\end{tabular}

Table 4 shows the type of accidents that occurred among the study subjects were shown in Table 5. It is seen from the table that road traffic accidents are the most common type of accident which is followed by fall and assault.

Table 5: Distribution of the study subjects based on the type of patellar fracture.

\begin{tabular}{|lll|}
\hline $\begin{array}{l}\text { Type of patellar } \\
\text { fracture }\end{array}$ & Frequency & $\begin{array}{l}\text { Percentage } \\
(\%)\end{array}$ \\
\hline Transverse fracture & 14 & 46 \\
\hline Vertical fracture & 6 & 20 \\
\hline $\begin{array}{l}\text { Comminuted } \\
\text { fracture }\end{array}$ & 8 & 26.6 \\
\hline Stellate fracture & 2 & 6.6 \\
\hline Total & 30 & 100 \\
\hline
\end{tabular}

Table 5 shows the distribution of the study subjects based on the type of patellar fracture. It is seen from the table that the transverse fracture of the patella is the commonest type of patella fracture followed by comminuted fracture and vertical fracture.

Table 6: Distribution of the study subjects based on the operative procedure.

\begin{tabular}{|lll|}
\hline $\begin{array}{l}\text { Operative procedure } \\
\text { Modified tension band } \\
\text { wiring }\end{array}$ & 12 & 40 \\
\hline $\begin{array}{l}\text { Cancellous screw } \\
\text { fixation with TBW }\end{array}$ & 4 & 13.3 \\
\hline $\begin{array}{l}\text { TBW with cerclage } \\
\text { wiring }\end{array}$ & 4 & 13.3 \\
\hline Partial patellectomy & 4 & 13.3 \\
\hline Cerclage wiring & 2 & 6.6 \\
\hline $\begin{array}{l}\text { Cancellous screw } \\
\text { fixation with cerclage } \\
\text { wiring }\end{array}$ & 2 & 6.6 \\
\hline $\begin{array}{l}\text { Cancellous screw } \\
\text { fixation }\end{array}$ & 1 & 3.3 \\
\hline Total patellectomy & 1 & 3.3 \\
\hline Total & 30 & 100 \\
\hline
\end{tabular}

Table 6 shows the various operative procedures performed for fracture patella among the study subjects. It is depicted from the table that the most common operative procedure done among the patella fracture patients was modified tension band wiring and the other procedures performed were fixing with cancellous screws and cerclage wiring. Partial patellectomy was done on 4 patients and total patellectomy was done for only one patient.

Table 7 shows the various type of operative procedures performed for the various type of patella fractures. Transverse patella fracture is being the most common fracture and for that modified tension band wiring was the most common procedure performed and for comminuted fracture partial patellectomy was the most common 
procedure and for 1 patient total patellectomy was performed. Cerclage wiring is mainly done for stellate fractures and vertical type of patella fractures cancellous screws along with tension band wiring was the most commonly performed procedure.

Table 8 shows the distribution of the study subjects based on the West criteria grading. The functional outcome of the knee after the patella surgery was assessed using West criteria grading. It was assessed using the following criteria a limitation of activities, flexion and extension range, extensor lag, subjective complaints, and quadriceps wasting or subsequent reduction in power. It is depicted from the table that more than $75 \%$ of the patients had excellent grading and $20 \%$ had a good outcome and only one patient had a poor functional outcome.

Table 7: Types of patellar fractures and the various modalities of operative techniques.

\begin{tabular}{|c|c|c|c|c|c|c|c|c|c|}
\hline \multirow[b]{2}{*}{$\begin{array}{l}\text { Type of } \\
\text { fracture }\end{array}$} & \multicolumn{8}{|c|}{ Operative procedure } & \multirow[b]{2}{*}{ Total } \\
\hline & $\begin{array}{l}\text { CS } \\
\text { fixation } \\
\text { with } \\
\text { TBW }\end{array}$ & $\begin{array}{l}\text { ORIF } \\
\text { with } \\
\text { CS }\end{array}$ & $\begin{array}{l}\text { ORIF } \\
\text { with CS } \\
\text { and } \\
\text { cerclage } \\
\text { wiring }\end{array}$ & $\begin{array}{l}\text { ORIF } \\
\text { with } \\
\text { TBW } \\
\text { and } \\
\text { cerclage } \\
\text { wiring }\end{array}$ & $\begin{array}{l}\text { ORIF } \\
\text { with } \\
\text { cerclage } \\
\text { wiring }\end{array}$ & $\begin{array}{l}\text { ORIF } \\
\text { with } \\
\text { modified } \\
\text { TBW }\end{array}$ & $\begin{array}{l}\text { Total } \\
\text { patellecto } \\
\text { my }\end{array}$ & $\begin{array}{l}\text { partial } \\
\text { patellec } \\
\text {-tomy }\end{array}$ & \\
\hline $\begin{array}{l}\text { Comminuted } \\
\text { fracture of } \\
\text { patella }\end{array}$ & 0 & 0 & 0 & 3 & 0 & 0 & 1 & 4 & 8 \\
\hline $\begin{array}{l}\text { Stellate } \\
\text { fracture }\end{array}$ & 0 & 0 & 0 & 0 & 2 & 0 & 0 & 0 & 2 \\
\hline $\begin{array}{l}\text { Transverse } \\
\text { fracture }\end{array}$ & 2 & 0 & 1 & 1 & 0 & 10 & 0 & 0 & 14 \\
\hline $\begin{array}{l}\text { Vertical } \\
\text { fracture of } \\
\text { patella } \mathbf{L t} \\
\text { knee }\end{array}$ & 2 & 1 & 1 & 0 & 0 & 2 & 0 & 0 & 6 \\
\hline Total & 4 & 1 & 2 & 4 & 2 & 12 & 1 & 4 & 30 \\
\hline
\end{tabular}

Table 8: Distribution of the study subjects based on the grading of west criteria.

\begin{tabular}{|lll|}
\hline West criteria & Frequency & Percentage $(\%)$ \\
\hline Excellent & 23 & 76.6 \\
\hline Good & 6 & 20 \\
\hline Poor & 1 & 3.3 \\
\hline Total & 30 & 100 \\
\hline
\end{tabular}

Table 9: Comparison of various operative procedure for fracture patella and their functional outcome measured by using West criteria grading system.

\begin{tabular}{|lllll|}
\hline Operative procedure & West criteria grading & \multicolumn{2}{c|}{ Total } \\
\hline Modified tension band wiring & Excellent & Good & Poor & 12 \\
\hline Cancellous screw fixation with TBW & 12 & 0 & 0 & 4 \\
\hline TBW with cerclage wiring & 4 & 0 & 0 & 4 \\
\hline Partial patellectomy & 4 & 0 & 0 & 4 \\
\hline Cerclage wiring & 0 & 4 & 0 & 2 \\
\hline Cancellous screw fixation with cerclage wiring & 2 & 0 & 0 & 2 \\
\hline Cancellous screw fixation & 1 & 1 & 0 & 1 \\
\hline Total patellectomy & 0 & 1 & 0 & 1 \\
\hline Total & 0 & 0 & 1 & 30 \\
\hline
\end{tabular}

Table 9 shows, $\mathrm{p}$ value derived by using the Chi-square test along with Fischer's exact test as most of the columns had numbers less than 5. Table 9 shows the comparison of various operative procedures for fracture patella and their functional outcome measured by using the West criteria grading system. It is inferred from the table that poor functional outcome was only reported in total patellectomy patients and a good outcome was reported among patients who underwent cancellous screw fixation and the excellent outcome was seen in patients who had undergone patellar 
repair with modified tension band wiring and a statistically significant association was seen between the type of procedure and the functional outcome $(\mathrm{p}<0.05)$.

\section{DISCUSSION}

Patellar fractures are common injuries resulting in loss of knee function due to direct or indirect trauma. It constitutes about $1 \%$ of all skeletal injuries. The subcutaneous location of the patella makes it more prone to direct injuries and indirect fractures of the patella due to forceful contraction of the quadriceps. The majority of the displaced transverse patellar fractures thus need reduction and internal fixation. ${ }^{11}$ For the fixation of this type of fracture, it is important to address the biomechanics of the construct. Thus, proper and adequate treatment is required to prevent disability due to patellar fracture. Many patellar fractures are not displaced and may be treated conservatively. Indications for surgical management include displacement $>2 \mathrm{~mm}$, a step-off involving the articular surface, or the inability to extend the knee actively. ${ }^{12}$ As with any intra-articular fracture, the goals of surgical treatment are to obtain an anatomic reduction and restore normal joint function while achieving bony union. ${ }^{13}$ Many surgeons maintain cast immobilization for three to six weeks. The previous result has demonstrated that patients with diminished range of motion had experienced prolong cast immobilization. ${ }^{14}$ This can best be avoided by initiating early knee movement. Ideally, knee movement should be started in the immediate postoperative setting since motion aids in the prevention of intra and periarticular fibrosis and having salutary effects on healing articular cartilage. ${ }^{15}$ Internal fixation of patellar fracture is to achieve fixation that is strong enough to allow an immediate range of motion. Several techniques have been described for the internal fixation of a fracture of the patella. Satisfactory compression at a fracture site reduces the risk of failure of fixation, loss of reduction (inter-fragmentary gap $>2 \mathrm{~mm}$ ), and subsequent risks of mal-union, delayed union, and ultimately non-union from exercise movement. ${ }^{16}$ Recently modified tension band wiring is a widely used technique in many orthopedic clinics for such fracture fixation. ${ }^{17}$ In this prospective study, 30 patellar fracture cases were treated with different types of operative procedures, and the functional outcome was assessed at the end of 6 months using the West criteria grading system and the results were recorded. ${ }^{18}$ In the present series, most of the patients had a direct mode of injury. In the series reported by Koval and the series reported by Singh also the majority of patients had a direct mode of injury. ${ }^{19}$ In our study, we found road traffic accident as the most common cause for patella fracture followed by fall from height whereas a study stated that the commonest mode of injury was fall on the knee, which was seen in 12 cases i.e., $60 \%$ of cases and the rest $40 \%$ had a road traffic accident. ${ }^{20}$ The present study indicates that transverse patella fracture is the most common type of fracture occurring in the patella followed by comminuted fracture and a similar type of pattern was also observed. ${ }^{21}$ The duration between the time of injury and surgery was
2.91 days (range 1-8 days). It was noted in our study that the delay in 7 cases was due to patients reporting late to the hospital. In our series, an associated injury was recorded in only one patient which was an ipsilateral undisplaced tibial shaft fracture. ${ }^{22}$ Modified tension band wiring (AO) was the most frequent technique of internal fixation, which in our patients we used in 20 out of 30 fracture patella cases. Out of these, tension band wiring modified with K-wires was used in 12 and that modified with cannulated cancellous screws in 4 patients and along with cerclage wiring in 4 patients. ${ }^{23} 21$ cases were treated with partial patellectomy and 7 cases were treated conservatively. out of 32 cases 10 cases were treated with internal fixation, 12 cases were treated with partial patellectomy and 10 cases were treated with total excision. It is observed by several authors that modified tension band wiring allowed for earlier knee mobilization compared to other techniques, which is the goal in the operative treatment of patella fractures. ${ }^{24}$ We agree with this observation. The average time taken for radiological evidence of fracture union after fixation in our study was 16 weeks. Berg observed that radiological union occurred at a mean of 13 weeks (range 8-24 weeks) Our study also proved a statistically significant association between the type of surgery and the functional outcome which showed results of open reduction, internal fixation is better as compared to patellectomy This suggests that one should opt for open reduction internal fixation for preserving the patella as far as possible.

\section{CONCLUSION}

As far as possible one should preserve patella whenever possible and osteosynthesis has a better chance for excellent results. The surgeon should avoid tilting of retained patellar fragments during the repair. A good surgical technique, optimal operation room environment, and judicious use of antibiotics will reduce the possibility of infection. In patella fractures, the most significant effects are loss of continuity of the extensor mechanism of the knee. The study shows that the treatment of patella fractures with modified tension band wiring is a definitive treatment with minimal complications and excellent functional outcomes. Early partial weight-bearing as tolerated with a posterior plaster splint is beneficial. The range of movement exercise should be started after 3 weeks when soft tissue healing is complete. Physiotherapy protocol plays an important role to improve final results. To overcome the late complications like osteoarthritis long term follow-up is recommended.

Funding: No funding sources

Conflict of interest: None declared

Ethical approval: The study was approved by the institutional ethics committee

\section{REFERENCES}

1. Wild M, Windolf J, Patellafrakturen FS. Fractures of the patella. Unfallchirurg. 2010;113(5):401-11. 
2. Lotke PA, Ecker ML. Transverse fractures of the patella. Clin Orthop Relat Res. 1981;(158):180-4.

3. Nummi J. Fracture of the patella. A clinical study of 707 patellar fractures. Ann Chir Gynaecol Fenn Suppl. 1971;179:1-85.

4. Scolaro J, Bernstein J, Ahn J. Patellar fractures. Clin Orthop Relat Res. 2011;469(4):1213-5.

5. Torchia ME, Lewallen DG. Open fractures of the patella. J Orthop Trauma. 1996;10(6):403-09.

6. Nomura E, Inoue M, Kurimura M. Chondral, and osteochondral injuries associated with acute patellar dislocation. Arthroscopy. 2003;19(7):717-21.

7. Ortiguera CJ, Berry DJ. Patellar fracture after total knee arthroplasty. J Bone Joint Surg Am. 2002;84A(4):532-40.

8. Berg EE. Management of patella fractures associated with central third bone-patella tendon-bone autograft ACL reconstructions. Arthroscopy. 1996;12(6):7569.

9. Bonus TJ, Alexander AH. Patellar fracture and avulsion of the patellar ligament complicating arthroscopic anterior cruciate ligament reconstruction. Orthop Rev. 1991;20(9):770-74.

10. Boström A. Fracture of the patella: A study of 422 patellar fractures. Acta Orthop Scand Suppl. 1972;143:1-80.

11. Atesok K, Doral MN, Lowe J, Finsterbush A. Symptomatic bipartite patella: Treatment alternatives. J Am Acad Orthop Surg. 2008;16(8):455-61.

12. Wiberg G. Roentgenographs and anatomic studies on the femoro-patellar joint: with special reference to chondromalacia patellae. Acta Orthop Scand. 1941;12:319-410.

13. Scapinelli R. Blood supply of the human patella. Its relation to ischaemic necrosis after a fracture. J Bone Joint Surg Br. 1967;49-B:563-70.
14. Shim SS, Leung G. Blood supply of the knee joint: A microangiographic study in children and adults. Clin Orthop Relat Res. 1986;208:1196.

15. Scolaro J, Bernstein J, Ahn J. Patellar fractures. Clin Orthop Relat Res. 2011;469(4):1213-5.

16. Kaufer H. Mechanical function of the patella. J Bone Joint Surg Am. 1971;53(8):1551-60.

17. Goldstein SA, Coale E, Weiss AP, Grossnickle M, Meller B, Matthews LS. Patellar surface strain. J Orthop Res. 1986;4(3):372-7.

18. Kaufer H. Mechanical function of the patella. J Bone Joint Surg Am. 1971;53(8):1551-60.

19. Koval KJ, Kim YH. Patella fractures. Evaluation and treatment. Am J Knee Surg. 1997;10(2):101-8.

20. Huberti HH, Hayes WC, Stone JL, Shy but GT. Force ratios in the quadriceps tendon and ligament patellae. J Orthop Res. 1984;2(1):49-54.

21. Bostrom MP, Asnis SE, Ernberg JJ, Wright TM, Giddings VL, Berberian WS, Missouri AA. Fatigue testing of cerclage stainless steel wire fixation. J Orthop Trauma. 1994;8(5):422-8.

22. Müller ME, Allgöwer M, Schneider R, Willenegger H. Manual of internal fixation, 2nd edn. Springer, Berlin Heidelberg New York. 1979;42-7.

23. Carpenter JE, Kasman R, Matthews LS. Fractures of the patella. J Bone Joint Surg Am. 1993;75:1550-61.

24. Scolaro J, Bernstein J, Ahn J. Patellar fractures. Clin Orthop Relat Res. 2011;469(4):1213-5.

25. Bumbaširević M, Lešić A. Acute injuries of the extensor mechanism of the knee. Current Orthop. 2005;19:49-58.

Cite this article as: Nikhilesh PS, Sivanandan $\mathrm{H}$, Anandanarayan M, Manoharan AE. Functional outcome of surgical management in cases of fracture patella in a tertiary care hospital in Salem. Int J Res Orthop 2021;7:507-12. 